\section{e-Journal of Educational \\ Research, Assessment and Evaluation}

\section{REIIEVE}

Revista ELectrónica de Investigación y EValuación

Educativa

\title{
ENFOQUES Y CONCEPCIONES DOCENTES EN LA UNIVERSIDAD
}

\section{[Teaching Approaches and Conceptions Taken by University Faculty]}

\author{
por
}

\section{$\underline{\text { Article record }}$ \\ About authors HTML format}

Ficha del artículo

$\underline{\text { Sobre los autores }}$

Formato HTML

\begin{abstract}
This study aims at identifying the teaching approaches and conceptions undertaken by faculty throughout their professional careers. Taking into consideration the phenomenographic research, but from a mixed-method research design, our analysis shows great variability in the ways professors express and understand their experiences and conceptions about teaching. They can be classified in: imparting knowledge, motivating students, developing skills and changing students' conceptions, or a combination of these. Categories are ordered from a higher to lower comprehension of teaching, and are progressive and inclusive. Teaching approaches are not related to age, experience, discipline or appointment, although there are some similarities among groups.
\end{abstract}

\section{Keywords}

Professional development, university teachers, academics, teaching conceptions, approaches to teaching.

\section{Resumen}

La investigación pretende conocer los enfoques y concepciones sobre docencia del profesorado universitario a lo largo de su trayectoria profesional. Desde la fenomenografía pero con enfoque metodológico mixto, nuestro análisis muestra gran variabilidad respecto cómo los docentes comprenden y expresan sus experiencias y concepciones sobre docencia. Éstas se pueden clasificar en: impartir conocimiento, entusiasmar y motivar, desarrollar habilidades y cambiar concepciones en los estudiantes; con combinaciones entre ellas. Las categorías se ordenan de mayor a menor comprensión de la docencia, son progresivas e inclusivas. Los enfoques docentes no tienen relación con la edad, experiencia, disciplina o categoría profesional aunque existen algunas similitudes entre grupos.

\section{Descriptores}

Desarrollo profesional, profesorado universitario, enfoque docente, concepciones docentes.
Las concepciones docentes del profesorado se entienden como el conjunto de significados especiales que los profesores otorgan a un fenómeno (en este caso la enseñanza y el aprendizaje) los cuales van a guiar la interpretación y la acción docente posterior. La investigación sobre las creencias y conocimiento del profesor ya era conocida en nuestro contexto (Marcelo, 1986; Calderhead, 1996, entre otros) pero menos conocidos eran los estudios sobre las concepciones de la enseñanza y el aprendizaje en el contexto de la educación superior. Sobre este tema ha sido más intensa y profunda la investigación en Australia, el Reino Unido y Hong Kong, iniciada en los años 90 y que ha tenido su posterior difusión e influencia sobretodo en los países escandinavos.

Un grupo considerable de investigadores empezaron a analizar los distintos significados de los términos enseñar y aprender en la 
universidad desde la experiencia y vivencias del profesorado y las intenciones subyacentes. Son de mencionar los primeros estudios sobre las concepciones y enfoques docentes de los académicos de Dall’Alba (1991), Martin y Balla (1991), Samuelowicz y Bain (1992, 2001), Martin y Ramsden (1992), Ramsden (1993), Gow y Kember (1993), Kember (1997), Marton y Säljö (1997), Murray y McDonald (1997), Pratt y Associates (1998), Prosser y Trigwell (1999), Samuelowicz y Bain (2001) y Norton et al. (2005).

A partir de éstos, surgieron nuevos estudios relacionando los enfoques docentes con el tipo de aprendizaje del estudiante (Kember y Gow, 1994; Trigwell, Prosser y Waterhouse, 1999), los enfoques docentes y la formación inicial del profesorado universitario (Gibbs y Coffey, 2000), la forma de experimentar los cambios y su comprensión de la materia (Trigwell et al., 2005), las percepciones del entorno académico o de las culturas disciplinarias con las orientaciones docentes (Prosser and Trigwell, 1997 and LindblomYlänne et al. 2007, respectivamente), las maneras de concebir la docencia efectiva (Carnell, 2007) o el ejercicio de "agencia" entre los profesores noveles desde la teoría social realista (Kahn, 2009).

Los logros más significativos de los principales estudios mencionados se comentan a continuación:

En uno de los primeros trabajos sobre las concepciones de la docencia desde la perspectiva de los aprendizajes de los estudiantes, Dall'Alba (1991) entrevistó a 20 docentes de universidades australianas de los ámbitos de la economía, inglés, medicina y física e identificó siete maneras diferentes de comprender la docencia en sus situaciones particulares de enseñanza y aprendizaje:

a) enseñar como presentar la información.

b) enseñar como transmitir la información (del docente a los estudiantes). c) enseñar como ilustrar la aplicación de la teoría a la práctica.

d) enseñar como desarrollar conceptos/principios y sus relaciones.

e) enseñar como desarrollar la capacidad de ser experto.

f) enseñar como explorar maneras de comprender desde diferentes perspectivas.

g) enseñar como producir cambios conceptuales.

Las categorías descritas se ordenan de menor a mayor comprensión de la docencia. En el nivel inferior, la enseñanza es vista en términos de lo que hace el profesor, principalmente sólo. De allí el centro de atención pasa a incorporar el contenido y desarrollar conceptos, a niveles superiores donde la comprensión de los estudiantes es esencial. Finalmente la concepción más completa se centra en la relación entre el profesor, los estudiantes y el contenido (Dall'Alba, 1991).

Dunkin (1990) dedujo cuatro dimensiones de docencia, utilizando el análisis de contenido de 55 entrevistas con docentes recientemente titulados. Éstas eran: estructurar el aprendizaje, motivar el aprendizaje, animar actividades de aprendizaje autónomo y establecer relaciones interpersonales dirigidas al aprendizaje.

También Pratt y cols. (1998), basándose en los resultados de una de las mayores muestras (253 adultos de entornos culturales variados), utilizó un enfoque fenomenográfico para identificar cinco concepciones de docencia:

a) la concepción de ingeniería: preocupada por la presentación de contenido y dirigida por el profesor,

b) la concepción del estudiante, que modela maneras de ser con el docente y el contenido como elementos predominantes,

c) la concepción de desarrollo o cultivar el intelecto: centrada en el estudiante y preocupada por facilitar el desarrollo intelec- 
tual y la autonomía personal de los estudiantes,

d) la concepción de atención y cuidado: con el objetivo principal del desarrollo del autoconcepto de los estudiantes, y

e) el concepto de reforma y cambio social, o búsqueda de una sociedad mejor.

Partiendo de los trabajos de Biggs, Dall'Alba y Martin y Balla, Ramsden (1993) sintetizó en tres las maneras de entender el rol del profesor en universidad: 1) la transmisión de conocimiento, 2) la organización de la actividad del estudiante, y 3) hacer posible el aprendizaje. Este autor considera el proceso como progresivo o jerárquico.

Los estudios de Kember y Gow (1994), a partir de sus investigaciones en Hong Kong, identificaron dos posibles orientaciones o concepciones de docencia: la transmisión de conocimiento o la facilitación de los aprendizajes. Las categorías se identificaron a partir de 39 entrevistas semiestructuradas que supusieron la base de un cuestionario. Los encuestados podían estar de acuerdo o no con las categorías que ofrecían en una escala Likert de cinco puntos. La muestra incluía dos instituciones diferentes y una variedad de áreas de conocimiento. El análisis factorial de las respuestas a los 46 ítems mostró una separación clara entre las dos orientaciones y aparecieron subescalas en cada una de estas orientaciones.
El trabajo más teórico que empírico de Biggs y Moore (1993) sugirió una aproximación jerárquica que iba de un enfoque cuantitativo de transmisión del conocimiento, hacia un enfoque cualitativo en el que el profesorado facilita la comprensión del significado, a una visión más amplia y un cambio en el estudiante. Estos autores asumen que el tercer nivel es 'superior' a los niveles inferiores.

Los primeros dos niveles se centran en el docente: el profesor controlando el contenido y el uso apropiado de las destrezas docentes. El tercer nivel es una aproximación centrada en el estudiante en el cual el aprendizaje es el resultado de la interacción entre los participantes y el papel del docente es involucrar a los estudiantes en actividades de aprendizaje efectivo.

Prosser et al. (1994), desde la perspectiva fenomenográfica, analizan las concepciones de la docencia desde dos dimensiones: a) la dimensión estructural o como se imparte la docencia (transmisión de información, ayudar a los estudiantes a adquirir conceptos, ayudar a los estudiantes a desarrollar concepciones y ayudar a los estudiantes al cambio de concepciones) y b) la dimensión referencial o de donde proviene el conocimiento (del programa, del docente o del estudiante). El resultado de las diferentes combinaciones sugiere seis categorías (Tabla 1):

Tabla 1. Concepciones de la docencia (Prosser et al., 1994)

\begin{tabular}{|c|c|c|c|}
\hline Como se da la explicación & \multicolumn{3}{|c|}{ De donde proviene el conocimiento (referencial) } \\
\cline { 2 - 4 } (estructural) & $\begin{array}{c}\text { Programa / conceptos } \\
\text { de un texto }\end{array}$ & $\begin{array}{c}\text { Conocimiento del } \\
\text { docente }\end{array}$ & $\begin{array}{c}\text { Conocimiento de los } \\
\text { estudiantes }\end{array}$ \\
\hline Transmitir información \\
$\begin{array}{l}\text { Ayudar a los estudiantes a } \\
\text { adquirir conceptos } \\
\text { Ayudar a los estudiantes a } \\
\text { desarrollar concepciones } \\
\text { Ayudar a los estudiantes a } \\
\text { cambiar concepciones }\end{array}$ & $\mathbf{A}$ & $\mathbf{B}$ & \\
\cline { 2 - 4 } & & $\mathbf{D}$ & $\mathbf{E}$ \\
\hline
\end{tabular}


Los docentes conciben la enseñanza como:

- (A) transmisión de los conceptos del programa

- (B) transmisión del conocimiento del profesor

- (C) ayudar los estudiantes a adquirir conceptos del programa o de un texto

- (D) ayudar los estudiantes a adquirir el conocimiento del profesor

- (E) ayudar los estudiantes a desarrollar concepciones

- (F) ayudar los estudiantes a cambiar concepciones

Las cuatro primeras concepciones son de docentes preocupados por transmitir información de un libro de texto, de un programa o su propio conocimiento. Las otras dos concepciones, E y $\mathrm{F}$, ven la enseñanza como ayudar a los estudiantes a desarrollar o cambiar la manera como entienden una realidad concreta.

Trigwell y Prosser (1996a/1996b) relacionan las concepciones del profesorado sobre docencia con las competencias docentes y demuestran que aquellos docentes que consi- deran el aprendizaje como información también entienden la docencia como la transmisión de información a los estudiantes y utilizan estrategias didácticas centradas en el profesor. En cambio, aquellos que creen que aprender supone un cambio y desarrollo de las concepciones de los estudiantes, definen enseñar en términos de ayudar a los estudiantes a desarrollar y cambiar sus concepciones y enfocan su docencia desde el punto de vista del alumnado.

Prosser y Trigwell (1999) idearon el Approaches to Teaching Inventory (ATI) para identificar el tipo de enfoque docente del profesor universitario. El ATI confronta las intenciones y estrategias de los docentes que presentan un enfoque centrado en ellos mismos y su enseñanza o un enfoque centrado en los aprendizajes de los estudiantes. A partir de los resultados, fruto de la aplicación del cuestionario a miles de académicos en el contexto internacional, identificaron la existencia de distintos enfoques sobre la docencia y diferentes concepciones sobre la enseñanza y el aprendizaje (Tabla 2):

Tabla 2: Enfoques y concepciones docentes según Prosser y Trigwell (1999)

\begin{tabular}{|l|l|l|}
\hline \multicolumn{1}{|c|}{\begin{tabular}{c}
\multicolumn{1}{|c|}{$\begin{array}{c}\text { Perspectivas teóricas sobre la } \\
\text { docencia: }\end{array}$} \\
$\begin{array}{l}\text { Perspectiva A: Estrategia centrada en el } \\
\text { profesor con la intención de transmitir } \\
\text { conocimiento }\end{array}$
\end{tabular} $\begin{array}{l}\text { Concepción A: enseñanza como trans- } \\
\text { misión de los conceptos de un programa }\end{array}$} & $\begin{array}{l}\text { Concepción A: aprendizaje como acu- } \\
\text { mulación de información para satisfacer } \\
\text { demandas externas }\end{array}$ \\
\hline $\begin{array}{l}\text { Perspectiva B: Estrategia centrada en el } \\
\text { profesor con la intención de que los } \\
\text { estudiantes adquieran los conceptos de } \\
\text { la asignatura }\end{array}$ & $\begin{array}{l}\text { Concepción B: enseñanza como trans- } \\
\text { misión del conocimiento del profesora- } \\
\text { do }\end{array}$ & $\begin{array}{l}\text { Concepción B: aprendizaje como ad- } \\
\text { quisición de conceptos para satisfacer } \\
\text { demandas externas }\end{array}$ \\
\hline $\begin{array}{l}\text { Perspectiva C: Estrategia centrada en la } \\
\text { interacción entre el profesor y el estu- } \\
\text { diante con la intención de que los estu- } \\
\text { diantes adquieran los conceptos de la } \\
\text { asignatura }\end{array}$ & $\begin{array}{l}\text { Concepción C: enseñanza como ayuda a } \\
\text { los estudiantes a adquirir los conceptos } \\
\text { del programa. }\end{array}$ & $\begin{array}{l}\text { Concepción C: aprendizaje como ad- } \\
\text { quisición de conceptos para satisfacer } \\
\text { demandas internas }\end{array}$ \\
\hline $\begin{array}{l}\text { Perspectiva D: Estrategia centrada en el } \\
\text { estudiante con el objetivo que los estu- } \\
\text { diantes desarrollen sus concepciones. }\end{array}$ & $\begin{array}{l}\text { Concepción D: enseñanza como ayuda } \\
\text { a los estudiantes a adquirir el conoci- } \\
\text { miento del profesor }\end{array}$ & $\begin{array}{l}\text { Concepción D: aprendizaje como desa- } \\
\text { rrollo conceptual para satisfacer de- } \\
\text { mandas internas }\end{array}$ \\
\hline $\begin{array}{l}\text { Perspectiva E: Estrategia centrada en el } \\
\text { estudiante con el objetivo de que los } \\
\text { estudiantes cambien sus concepciones }\end{array}$ & $\begin{array}{l}\text { Concepción E: enseñanza como ayuda a } \\
\text { los estudiantes a desarrollar concepcio- } \\
\text { nes } \\
\text { Concepción F: enseñanza como ayuda a } \\
\text { los estudiantes a cambiar las concep- } \\
\text { ciones }\end{array}$ & $\begin{array}{l}\text { Concepción E: aprendizaje como cam- } \\
\text { bio conceptual para satisfacer demandas } \\
\text { internas }\end{array}$ \\
&
\end{tabular}


Murray y McDonald (1997) compilaron los estudios sobre las concepciones y enfoques docentes del profesorado universitario realizados hasta el momento (Tabla 3) y llegaron a dos conclusiones: que las respuestas sobre las concepciones docentes se pueden distribuir en cuatro áreas: a) impartir conocimiento, b) entusiasmar, estimular y motivar los estudiantes, c) facilitar los aprendizajes de los estudiantes, y d) apoyar a los estudiantes; y que existen combinaciones variadas entre estas posibles respuestas.

Desde el punto de vista de Åkerlind (2003), estos estudios tienen en común maneras diversas de concebir la docencia puesto que todos se centran en a) la transmisión de información a los estudiantes vs. el desarrollo de la comprensión en los estudiantes; y en b) el profesor y las estrategias de enseñanza vs. los estudiantes y su aprendizaje y desarrollo.

Por otro lado, algunas investigaciones se han llevado a cabo desde una perspectiva fenomenográfica, donde las diferentes concepciones sobre docencia manifiestan representaciones de diferente nivel de concienciación sobre el fenómeno de la docencia, construidas de la relación experiencial entre el docente y el fenómeno. Otros estudios se han llevado a cabo desde una perspectiva cognitivista donde las diferentes concepciones son reflejo de diferentes creencias sobre docencia asociadas a diferentes representaciones mentales del fenómeno, construidas a partir de la experiencia del individuo (Åkerlind, 2007).

Los estudios de Samuelowicz y Bain (1992), Pratt y Associates (1992); Gow y
Kember (1993); Kember (1997); Murray y Macdonald (1997) formarían parte de las investigaciones realizadas desde una perspectiva cognitivista puesto que las diferentes visiones de la docencia se constituyen como elementos independientes, aunque se ordenen en un continuo en lo relativo a la sofisticación de las concepciones. Y, por otro lado, la perspectiva fenomenográfica incluiría los estudios de Dall'Alba (1991), Martin y Balla (1991); Martin y Ramsden (1992); Prosser y Trigwell (1999) y Åkerlind (2003, 2004, 2007) puesto que las diferentes visiones de docencia que emergen se relacionan en una jerarquía de inclusividad.

Los resultados de la investigación de Åkerlind (2007) también presentan este vínculo en las maneras de comprender la docencia desde una jerarquía de inclusividad. Al explorar las experiencias de enseñanza del profesorado y en concreto al examinar como crecen profesionalmente y cambian sus concepciones docentes, describe tres maneras cualitativamente distintas de entender el desarrollo:

- el confort del profesor con la docencia, en términos de sentirse más confiado como docente o encontrar la docencia menos costosa,

- el conocimiento y las habilidades del profesor, en términos de expandir el conocimiento de la materia y los materiales docentes, y/o expandir su repertorio de experiencias docentes, $\mathrm{y}$

- los resultados de aprendizaje de los estudiantes, en términos de mejorar el aprendizaje y desarrollo del estudiante. 
Feixas, Mònica (2010). Enfoques y concepciones docentes en la universidad. RELIEVE, v. 16, n. 2, p. 1-27. http://www.uv.es/RELIEVE/v16n2/RELIEVEv16n2_2.htm

Tabla 3. Resultados de investigaciones sobre concepciones de la docencia (adaptado de Murray y McDonald, 1997)

\begin{tabular}{|c|c|c|c|c|c|c|c|c|c|}
\hline $\begin{array}{c}\text { Fox } \\
(1983)\end{array}$ & $\begin{array}{c}\text { Dunkin } \\
(1990)\end{array}$ & $\begin{array}{c}\text { Kember y Gow } \\
(1990)\end{array}$ & $\begin{array}{l}\text { Dall'Alba } \\
\text { (1991) }\end{array}$ & $\begin{array}{l}\text { Pratt } \\
(1992)\end{array}$ & $\begin{array}{c}\text { Samuelowicz y } \\
\text { Bain } \\
(1992) \\
\end{array}$ & Ramsden (1993) & $\begin{array}{l}\text { Biggs y } \\
\text { Moore } \\
(1993) \\
\end{array}$ & $\begin{array}{l}\text { Murray y } \\
\text { Macdonald } \\
\text { (1997) }\end{array}$ & $\begin{array}{c}\text { Prosser et al. } \\
\text { (1994) } \\
\text { Prosser y } \\
\text { Trigwell (1999) } \\
\end{array}$ \\
\hline $\begin{array}{c}\text { Centrado en el } \\
\text { profesor y en la } \\
\text { materia } \\
\text { A }\end{array}$ & $\begin{array}{l}\text { Estructuración } \\
\text { del aprendizaje }\end{array}$ & $\begin{array}{l}\text { Transmitir co- } \\
\text { nocimiento }\end{array}$ & \multirow{5}{*}{\begin{tabular}{|c|} 
Presentar \\
información \\
A \\
Transmitir in- \\
formación \\
B \\
Ilustrar la \\
aplicación de la \\
teoría a la prác- \\
tica \\
C \\
Desarrollar \\
conceptos/ \\
principios y sus \\
relaciones \\
D \\
Desarrollar la \\
capacidad de ser \\
experto \\
E \\
Explorar \\
maneras de \\
comprender \\
desde diferentes \\
perspectivas \\
F \\
Producir \\
cambios concep- \\
tuales \\
G
\end{tabular}} & $\begin{array}{l}\text { Ingeniería: Im- } \\
\text { partición de } \\
\text { contenido } \\
\text { Aprendiz: mode- } \\
\text { lar maneras de } \\
\text { ser }\end{array}$ & $\begin{array}{c}\text { Impartir infor- } \\
\text { mación o esta- } \\
\text { blecer un marco } \\
\text { de referencia }\end{array}$ & $\begin{array}{l}\text { Enseñanza como } \\
\text { transmisión o } \\
\text { explicación }\end{array}$ & $\begin{array}{l}\text { Transmitir co- } \\
\text { nocimiento }\end{array}$ & $\begin{array}{c}\text { Impartir } \\
\text { conocimiento }\end{array}$ & $\begin{array}{c}\text { Transmitir los } \\
\text { conceptos de un } \\
\text { programa } \\
\text { A } \\
\text { Transmitir el } \\
\text { conocimiento } \\
\text { del profesor } \\
\text { B } \\
\end{array}$ \\
\hline $\begin{array}{c}\text { Centrado en el } \\
\text { profesor y cambio } \\
\text { en el estudiante } \\
\text { B }\end{array}$ & Motivación & & & $\begin{array}{l}\text { Desarrollo: } \\
\text { cultivar el } \\
\text { intelecto }\end{array}$ & $\begin{array}{l}\text { Transmitir co- } \\
\text { nocimiento, } \\
\text { conceptos y } \\
\text { habilidades }\end{array}$ & $\begin{array}{l}\text { Enseñanza como } \\
\text { el hecho de } \\
\text { organizar la } \\
\text { actividad del } \\
\text { estudiante }\end{array}$ & $\begin{array}{l}\text { Organizar las } \\
\text { destrezas } \\
\text { docentes }\end{array}$ & Motivar & $\begin{array}{l}\text { Ayudar a los } \\
\text { estudiantes a } \\
\text { adquirir } \\
\text { conceptos del } \\
\text { programa } \\
\text { C } \\
\end{array}$ \\
\hline $\begin{array}{c}\text { Centrado en el } \\
\text { estudiante y en la } \\
\text { materia } \\
\text { C }\end{array}$ & $\begin{array}{c}\text { Independencia y } \\
\text { actividades }\end{array}$ & $\begin{array}{c}\text { Facilitar el apren- } \\
\text { dizaje }\end{array}$ & & $\begin{array}{c}\text { Atención y } \\
\text { cuidado: promo- } \\
\text { ver aspectos de } \\
\text { la personalidad }\end{array}$ & $\begin{array}{c}\text { Facilitar la com- } \\
\text { prensión }\end{array}$ & $\begin{array}{c}\text { Enseñanza como } \\
\text { hacer posible el } \\
\text { aprendizaje }\end{array}$ & $\begin{array}{l}\text { Facilitar lel } \\
\text { aprendizaje }\end{array}$ & Facilitar & $\begin{array}{c}\text { Ayudar a los } \\
\text { estudiantes a } \\
\text { adquirir el cono- } \\
\text { cimiento del } \\
\text { profesor } \\
\text { D } \\
\end{array}$ \\
\hline \multirow[t]{2}{*}{$\begin{array}{c}\text { Centrado en el } \\
\text { estudiante y en el } \\
\text { cambio en el } \\
\text { estudiante } \\
\text { D } \\
\end{array}$} & \begin{tabular}{|c|} 
Relaciones inter- \\
personales
\end{tabular} & & & & $\begin{array}{c}\text { Dar apoyo al } \\
\text { aprendizaje del } \\
\text { estudiante }\end{array}$ & & & $\begin{array}{l}\text { Dar apoyo al } \\
\text { estudiante }\end{array}$ & $\begin{array}{c}\text { Ayudar a los } \\
\text { estudiantes a } \\
\text { desarrollar con- } \\
\text { cepciones } \\
\text { E } \\
\end{array}$ \\
\hline & & & & $\begin{array}{l}\text { Reforma social: } \\
\text { buscar un } \\
\text { mundo mejor }\end{array}$ & $\begin{array}{l}\text { Cambiar las } \\
\text { concepciones } \\
\text { del estudiante }\end{array}$ & & & & $\begin{array}{c}\text { Ayudar a los } \\
\text { estudiantes a } \\
\text { cambiar } \\
\text { concepciones } \\
\text { F } \\
\end{array}$ \\
\hline $\begin{array}{c}\text { Teorías } \\
\text { docentes }\end{array}$ & $\begin{array}{c}\text { Dimensiones de } \\
\text { la docencia }\end{array}$ & $\begin{array}{l}\text { Orientaciones } \\
\text { docentes }\end{array}$ & $\begin{array}{l}\text { Concepciones de } \\
\text { la docencia }\end{array}$ & $\begin{array}{l}\text { Concepciones de } \\
\text { la docencia }\end{array}$ & $\begin{array}{c}\text { Concepciones de } \\
\text { la docencia }\end{array}$ & $\begin{array}{c}\text { Teorías } \\
\text { docentes }\end{array}$ & $\begin{array}{l}\text { Concepciones de } \\
\text { la docencia }\end{array}$ & $\begin{array}{l}\text { Concepciones de } \\
\text { la docencia }\end{array}$ & $\begin{array}{c}\text { Concepciones de } \\
\text { la docencia }\end{array}$ \\
\hline Teórico & Empírico & $\begin{array}{l}\text { Análisis de } \\
\text { contenido }\end{array}$ & Fenomenográfico & Fenomenográfico & Fenomenográfico & Teórico & Teórico & Cualitativo & Fenomenográfico \\
\hline
\end{tabular}

Revista ELectrónica de Investigación y EValuación Educativa [ www.uv.es/RELIEVE]

pag. 6 
Otro aspecto importante es entender que el enfoque docente del profesorado es relacional (Prosser y Trigwell, 1999, Åkerlind, 2003); es decir, más que ser una característica relativamente estable de un profesor, el enfoque cambia según las percepciones de su situación. Al respecto, Prosser y Trigwell (1999) sugieren que si los docentes perciben que controlan el qué y cómo enseñar, si el tamaño de la classe no es muy grande y su departamento valora la docencia, tienen más probabilidades de adoptar un enfoque docente centrado en el estudiante y el cambio conceptual. LindblomYlänne et al. (2007) comparten la necesidad de contextualizar el enfoque al encontrar diferencias entre los enfoques docentes de profesores en función de la disciplina y González (2009) entre los enfoques docentes y la docencia virtual.

En síntesis, y utilizando las ideas de Ramsden (1993), el profesorado universitario experimenta y comprende la enseñanza de distintas maneras, cada una con las correspondientes connotaciones e implicaciones sobre cómo se espera que los estudiantes aprendan.

\section{Teoría 1. Enseñanza entendida como transmi- sión o comunicación:}

Muchos docentes de universidad entienden la tarea de enseñar implícita o explícitamente como la transmisión de contenido o la demostración de procedimientos. El conocimiento auténtico del profesor debe ser inculcado a los estudiantes. La tradicional clase magistral es la representación suprema de la perspectiva docente del profesor como transmisor de información. Los estudiantes son recipientes pasivos de la sabiduría de un único comunicador. Es necesario y suficiente que sea un experto en la materia. El conocimiento que tiene y el conocimiento de las técnicas docentes se encuentran en compartimentos diferentes. La teoría muestra afinidades entre esta perspectiva y el aprendizaje memorístico. Se dará aprendizaje siempre que se muestre al estudiante el máximo de información posible.
Bajo esta teoría los docentes habitualmente atribuyen cualquier fracaso de aprendizaje a los estudiantes. Se conceptualiza como un modelo input-output; no se acaba de comprender muy bien porqué el estudiante no aprende después de haber sido expuesto a la enseñanza del profesor/a -probablemente porque no ha prestado suficiente atención en clase, por falta de voluntad, pereza al trabajar un tema, poca capacidad para absorber material nuevo, falta de preparación o formación previa. Se asocia la calidad del aprendizaje del estudiante con su capacidad y personalidad. Todos los problemas de aprendizaje son externos al profesor, el programa o la institución. Aumentar el nivel de exigencia en la entrada a la universidad parece ser un remedio al problema del aprendizaje insuficiente.

Esta teoría se sostiene debido a la creencia que los problemas fundamentales de la universidad provienen de la cantidad de información que debe ser transmitida, y de los numerosos grupos de estudiantes por asignatura. La única manera de resolver estos problemas es diseñar sesiones que ayuden a transmitir más información o más rápidamente (por ejemplo mediante vídeos, transparencias o programas informáticos).

Teoría 2. Enseñanza como organización de la actividad del estudiante:

En esta teoría, el centro de atención pasa del profesor al estudiante. La enseñanza es un proceso de supervisión que incluye la articulación de técnicas diseñadas a asegurar que el estudiante aprende. Su aprendizaje es visto como un problema complejo. Se procuran hacer muchas actividades porque se entiende que el aprendizaje se da por interacción. La metodología incluye la motivación de los estudiantes de manera que estén más predispuestos psicológicamente a aprender la asignatura. Se utilizan técnicas para promover la discusión, prácticas para relacionar el conocimiento teórico con su experiencia, como por ejemplo diferentes tipos de aprendizaje experiencial (Kolb, 1984). 
La enseñanza, bajo este punto de vista, no es vista como la simple transmisión de información, sino como la manera de tratar a los estudiantes para que aprendan: utilizando metodologías variadas, realizando trabajos en grupo... Corresponde al estadio de desarrollo de la mayoría de académicos que creen que esta es la manera de innovar en la educación superior. La mejora de la docencia tiene relación con ampliar el repertorio de técnicas y estrategias del docente, más que cambiar sus concepciones de la docencia. Aprender técnicas docentes es, bajo esta teoría, una base suficiente para mejorar la enseñanza. Se asume que si aprendemos como hacer algo, el aprendizaje sobre como reflexionar en aquello que hacemos y aplicar nuestro conocimiento a las nuevas situaciones ocurre de manera natural.

La visión del aprendizaje de los estudiantes correspondiente a esta teoría docente es que hay ciertas condiciones que garantizarán el aprendizaje. Si no se da aprendizaje, hay problemas con el entorno del estudiante y/o con él mismo. El aprendizaje del estudiante todavía es visto como un proceso aditivo, no como responsabilidad última del aprendiz. Esta teoría representa de muchas maneras el estadio transicional entre la teoría 1 y la teoría 3.

\section{Teoría 3. Enseñanza entendida como hacer posible el aprendizaje:}

"Las teorías 1 y 2 se centran en el docente y el estudiante respectivamente; la teoría 3 entiende la enseñanza y el aprendizaje como dos caras de una moneda." (Ramsden, 1993:114). La enseñanza es vista como la ayuda a los estudiantes para cambiar su comprensión de la materia, como trabajar cooperativamente con ellos para guiarlos en el cambio de concepciones, significa hacer posible el aprendizaje. Enseñar implica conocer las dificultades e incomprensiones de los estudiantes, intervenir para cambiarlas, crear un entorno de aprendizaje que anime activamente a los estudiantes a implicarse en la materia. Tiene más relación con el conte- nido, el qué se ha de aprender que el cómo porque el contenido y los problemas de los estudiantes con el aprendizaje dirigen los métodos que emplea el profesor.

El conocimiento lo construye de manera dinámica el estudiante mismo, y lo hace a partir de la aplicación y modificación de sus propias ideas. La diferencia de las otras teorías es que el conocimiento lo transforma el estudiante, no se le da transformado. En la línea de Bruner (1972), el conocimiento es un proceso, no un producto: "Un currículum no sólo refleja la naturaleza del conocimiento mismo, sino también la naturaleza del conocedor y del proceso de consecución del conocimiento" (p. 72).

Esta teoría muestra el concepto de enseñanza como una actividad reflexiva que busca la mejora constante de la docencia a partir de dar respuesta a las necesidades de los estudiantes y escuchando también los otros docentes. La mejora continua consiste en construir y elaborar el conocimiento profesional y reconceptualizar los hechos (Schön, 1992). Los docentes de esta perspectiva están interesados en aprender variedad de recursos sobre como mejorar su docencia.

Sus teorías muestran una estructura jerárquica y progresiva. La primera teoría asume que el conocimiento del contenido y la presentación fluida son necesarios para una buena docencia. La segunda teoría complementa este dibujo con destrezas adicionales de más técnicas docentes. La teoría tres presupone todas estas destrezas y comprende que la docencia debe ayudar a cambiar las concepciones de los estudiantes y enseñarles a desarrollar sus propias.

La teoría más sofisticada incluye aspectos de las anteriores, en el sentido que la docencia implica presentar información, motivar los estudiantes y crear oportunidades para que aprendan. Una buena clase magistral significa realizar una presentación clara y ordenada, y su último análisis sólo lo puede hacer el estudiante, es su responsabilidad; pero la buena docencia hace que el aprendizaje sea posible, 
delinea una manera de pensar sobre la docencia que es cualitativamente diferente y pedagógicamente superior a las teorías anteriores.

Estas teorías representan 'modelos ideales', son constructos lógicos más que meras descripciones de cada individuo o cada asignatura. Sin embargo, los profesores y profesoras excelentes y comprometidas realmente enseñan de manera parecida a la expuesta en la teoría 3. Hay una línea de desarrollo lógica de una teoría a la siguiente que constata el proceso de un docente aprendiendo sobre docencia.

\section{Objetivos y diseño metodológico}

Después de analizar detalladamente la literatura, tenemos presente un ideal implícito a partir de las teorías docentes de Ramsden (1993), conocemos las distintas categorizaciones de concepciones docentes en la educación superior de Murray y McDonald (1997), los enfoques docentes de Prosser y Trigwell (1999) y la jerarquía de inclusividad de las experiencias docentes presentadas por Åkerlind (2003, 2004, 2007). Ello nos ha llevado a investigar y descubrir qué enfoques docentes y concepciones sobre enseñanza y aprendizaje existen en la orientación y las prácticas educativas que describe el profesorado universitario.

$\mathrm{Al}$ respecto se nos plantean los siguientes interrogantes:

- ¿Qué concepciones tiene el profesorado universitario de nuestras universidades sobre enseñar y aprender en la universidad?

- ¿De qué manera enfocan la docencia? ¿Cuál es su estilo u orientación docente?

- ¿Son estas concepciones estables o varían en función de la trayectoria profesional, del área de conocimiento o del entorno docente del profesor/a?

- ¿Es posible cambiar las concepciones docentes del profesorado para poder dar respuesta a los retos que la sociedad del aprendizaje demanda?

- ¿El éxito del cambio profesional depende de las prioridades que se establece el mis- mo profesor/a o también está sujeto a la cultura de cada organización?

Para poder dar respuesta a estas preguntas nos planteamos el siguiente objetivo general: conocer las diferentes maneras que tiene el profesorado de experimentar y comprender la docencia en la universidad. Más concretamente, la investigación trata de:

- Identificar el enfoque docente que subyace a las prácticas educativas que describe el profesorado.

- Conocer las concepciones docentes del profesorado universitario, es decir, su comprensión sobre la enseñanza y el aprendizaje.

- Averiguar hasta qué punto cambian las concepciones o las estrategias docentes a lo largo de la trayectoria docente.

\section{Método}

Para abordar las preguntas de investigación precedentes, se propone un diseño de investigación basado en una metodología mixta. Johnson \& Onwuegbuzie (2004) distinguen entre los diseños de métodos mixtos (la inclusión de una fase cuantitativa y una fase cualitativa en el estudio) y los diseños de modelos mixtos (la mezcla de enfoques cuantitativos y cualitativos en o durante las fases del proceso de investigación). Un diseño de métodos mixtos puede variar en función de la secuencia de recogida de información y la prioridad o peso que se le atribuye a cada tipología de dato.

El objetivo de nuestra investigación es describir una situación y comprender el fenómeno del cambio en la docencia desde el punto de vista de los mismos docentes. En este trabajo se ha desarrollado un cuestionario y se han llevado a cabo entrevistas, ambos dirigidos a obtener una amplia representación de las miradas o concepciones del profesorado universitario sobre la docencia.

El Cuestionario sobre la Orientación Pedagógica del Profesorado Universitario tiene como principales marcos de referencia el tra- 
bajo de Ramsden (1993) y las concepciones docentes según Prosser y Trigwell (1999); también revisa las teorías sobre los estadios de desarrollo del profesorado universitario de Kugel (1993), Nyquist y Sprague (1998) y Robertson (1999). A partir de aquí se construye un primer cuestionario de 89 ítems (contiene más del $50 \%$ de los ítems de la versión final) que se administra a una muestra de 38 profesores, con el objetivo de seleccionar el mínimo de ítems necesarios para cada dimensión. Después del análisis de la fiabilidad (Alpha de Cronbach $=0,89$ ), se eliminan $\mathrm{y}$ modifican 29 ítems para obtener una versión reducida. El cuestionario final de 60 ítems (medidos de 1 a 5 en una escala de Likert) considera las siguientes dimensiones: Características del Docente (género, edad, estudios, categoría profesional, universidad, departamento, titulación, años de experiencia universitaria, formación pedagógica y tipo de curso y número aproximado de estudiantes matriculados, dedicación a docencia, investigación y/o gestión), Preocupaciones sobre Docencia, Concepciones sobre Enseñanza y Aprendizaje, Estrategias de Enseñanza y Aprendizaje y Relación con los Estudiantes (Alpha de Cronbach del cuestionario final $=0,83$ ).

El cuestionario incluye unas preguntas abiertas que pretenden conocer como definen enseñar y aprender, así como describen su estilo docente. También interrogan sobre el papel de la formación pedagógica entre otros factores que pueden instigar el cambio de las concepciones y prácticas docentes y la influencia de las funciones de investigación y gestión del profesorado en el desarrollo docente.

En este artículo presentamos los resultados obtenidos en una de las principales dimensiones del estudio: las concepciones del profesorado sobre la docencia. A pesar de que todas las dimensiones tienen clara relación entre sí, no podemos ahondar en todas ellas por cuestiones de espacio y amplitud.

\section{Muestra}

La muestra está formada por docentes de dos universidades de Catalunya tradicionalmente centradas en la investigación, la Universitat Autònoma de Barcelona (UAB) y la Universitat Politècnica de Catalunya (UPC), y representa una gran variabilidad en lo referente a experiencias, edad, titulación, situación profesional y formación pedagógica.

Para garantizar que la muestra sea representativa hemos realizado un proceso de selección probabilístico y estratificado mediante el cual hemos dividido la población total de la UAB en las áreas científicas en las que la institución clasifica a sus departamentos (ciencias sociales, ciencias de la salud, humanidades y tecnología y ingeniería) y hemos escogido una representación de doce departamentos, tres de cada área. En el caso de la UPC, puesto que la mayor parte de los estudios son de tecnología $\mathrm{y}$ ciencias experimentales, hemos escogido doce departamentos al azar. El cuestionario se ha enviado a todo el profesorado de estos departamentos, unos 1.600 aproximadamente.

Con la opinión contrastada del profesorado de los 24 departamentos universitarios se pretende llegar a una muestra representativa de la población que imparte docencia en las universidades de nuestro contexto; profesorado de categoría profesional, experiencia, edad, género, disciplina, formación pedagógica y distribución de su dedicación académica variada.

Para complementar los resultados del cuestionario, se han realizado 14 entrevistas semiestructuradas y en profundidad con el profesorado de los departamentos de la muestra, siete de cada universidad. Los entrevistados y entrevistadas han sido seleccionados intencionalmente también con el objetivo de mostrar el máximo de variación posible en las maneras de comprender y experimentar la docencia. Las preguntas versaban sobre sus preocupaciones y concepciones docentes, sus estrategias o manera de enfocar la docencia y la relación con sus estudiantes, las mismas dimensiones que aparecen en el cuestionario. 
Para la selección de los entrevistados y entrevistadas se consideraron los siguientes criterios:

- Edad (desde mediados de los 20 años hasta mediados de los 60).

- Género (7 hombres, 7 mujeres).

- Experiencia académica (desde pocos meses hasta 35 años).

- Disciplina: 1 de humanidades (historia), 4 de ciencias sociales (periodismo, sociología, derecho y económicas), 2 de ciencias de la salud (farmacología, psicología) y 7 de ingeniería.

- Categoría profesional: 2 catedráticos/as, 4 titulares, 2 ayudantes doctores, 4 asociados, 2 estudiantes posdoctorales y ayudantes no-doctores.

- Estudios universitarios: 5 con estudios superiores, 9 con estudios doctorales.

- Formación pedagógica: 4 sin formación, 2 con un curso de iniciación a la formación,
6 con algún taller sobre algún aspecto de didáctica universitaria, 1 con la carrera de magisterio, 1 con un master en educación.

- Enfoques docentes: 7 centrados en el profesor y la enseñanza, 7 centrados en el estudiante y el aprendizaje.

- Porcentaje dedicado a la docencia, investigación y gestión: del 20 al 70\% a la docencia, del 10 al $65 \%$ a la investigación, y de 0 a $50 \%$ a la gestión (en el caso de dos jefes de departamento).

Todas las entrevistas se han grabado y transcrito verbatim. Seguidamente se han analizado de forma iterativa lo que ha implicado revisar las respuestas varias veces para asegurar que tenían posibilidad de clasificarse algunas en las categorías consideradas a priori, otras, en las nuevas categorías aparecidas.

En concreto, la muestra de profesorado a entrevistar ha sido la siguiente (Tabla 4):

Tabla 4. Determinación de la muestra de profesorado a entrevistar

\begin{tabular}{|c|c|c|c|c|c|c|c|c|}
\hline & Edad & Titulación & $\begin{array}{l}\text { Categoria } \\
\text { Profesional }\end{array}$ & Créditos & $\begin{array}{l}\text { Experiencia } \\
\text { docente } \\
\text { universitaria }\end{array}$ & $\begin{array}{l}\text { Formación } \\
\text { pedagógica } \\
\text { acreditada }\end{array}$ & $\begin{array}{l}\text { \% docencia } \\
\text { investigación } \\
\text { y gestión }\end{array}$ & $\begin{array}{l}\text { Enfoque } \\
\text { pedagógico }\end{array}$ \\
\hline $\begin{array}{l}\text { UAB } \\
\text { M.B. Psicología } \\
\text { de la Educación }\end{array}$ & $\begin{array}{c}24 \\
\text { años }\end{array}$ & Licenciado & Asociado/ & $\begin{array}{l}\quad 8 \\
\text { Clases } \\
\text { prácti. }\end{array}$ & $\begin{array}{c}1 \text { año } \\
(+2 \text { años } \\
\text { exp.docent } \\
\text { no universi- } \\
\text { taria) } \\
\end{array}$ & No & $\begin{array}{l}D=70 \\
R=30 \\
G=0\end{array}$ & $\begin{array}{l}\text { Centrado en } \\
\text { el profesor } \\
\text { y su ense- } \\
\text { ñanza }\end{array}$ \\
\hline $\begin{array}{l}\text { UPC } \\
\text { O.A. Arquitect. } \\
\text { Comput. }\end{array}$ & $\begin{array}{c}29 \\
\text { años }\end{array}$ & $\begin{array}{l}\text { Licenciado } \\
\text { /Ingeniero }\end{array}$ & Asociado & $\begin{array}{l}18 \\
\text { Clases } \\
\text { prácti. }\end{array}$ & $\begin{array}{l}1 \text { año } \\
\text { Novel }\end{array}$ & No & $\begin{array}{l}D=45 \\
R=45 \\
G=10\end{array}$ & $\begin{array}{l}\text { Centrado en } \\
\text { el profesor } \\
\text { y su ense- } \\
\text { ñanza }\end{array}$ \\
\hline
\end{tabular}


Tabla 4. Determinación de la muestra de profesorado a entrevistar (continuación)

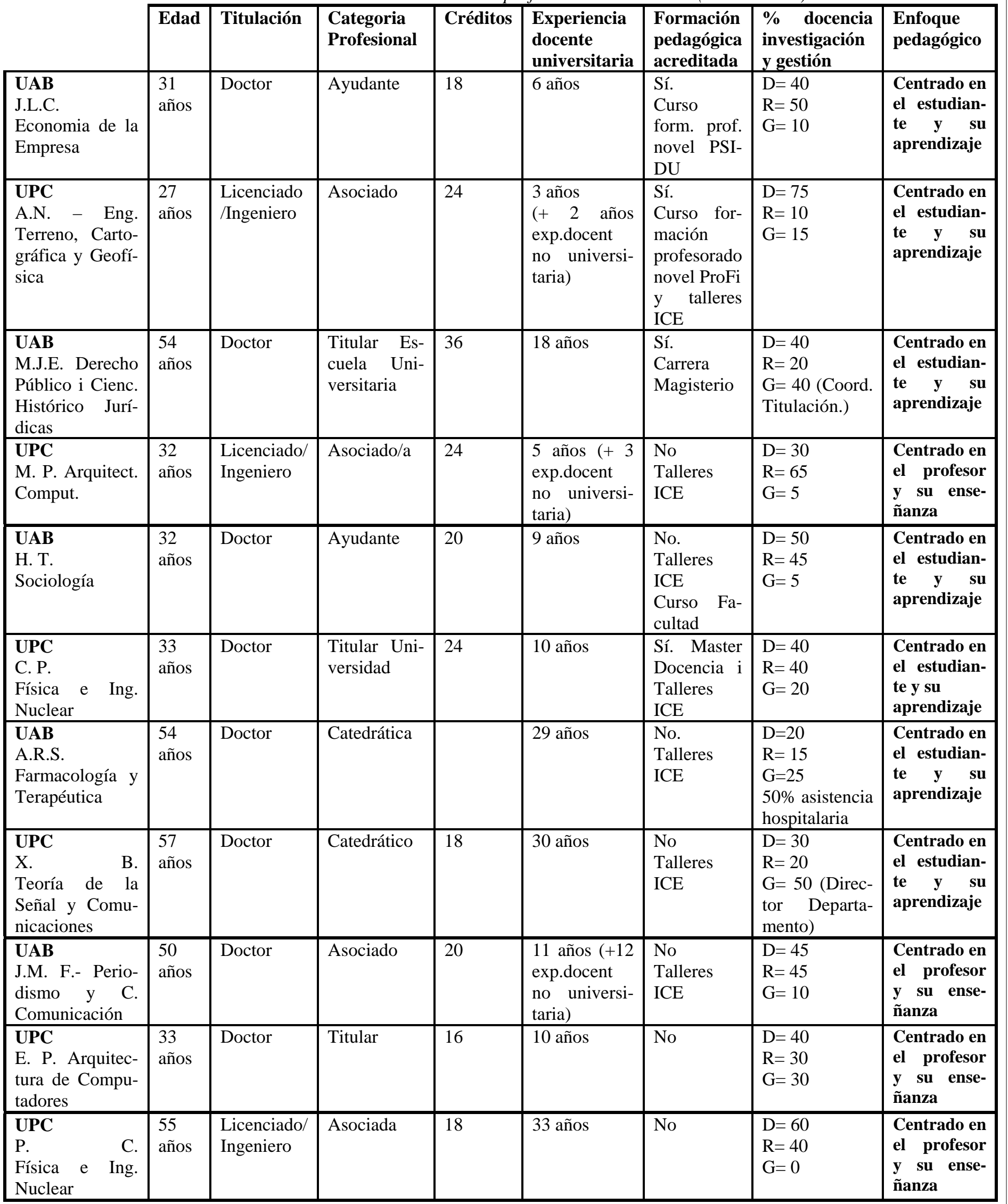




\section{Análisis de resultados}

\section{Análisis cuantitativo}

Se envió el cuestionario a las direcciones de los departamentos junto con una carta del Vicerectorado de Ordenación Académica que mostraba el apoyo al estudio. Las direcciones optaron por repartir y recoger los cuestionarios, pero el nivel de seguimiento y control fue muy variable. Tanto es así que en algún departamento no hubo devolución alguna.
Ello puede explicar el bajo número de respuestas en comparación con el total de la plantilla de los departamentos, aunque tampoco se trata de una cifra despreciable. Consiste en 253 cuestionarios que, si bien no permiten generalizar resultados, ofrecen evidencias importantes de la amplia variabilidad en los significados y concepciones que los docentes atribuyen a la enseñanza y aprendizaje. La tabla 5 informa de la población y la muestra:

Tabla 5: Número total de cuestionarios recibidos y contestados por universidad y departamento

\begin{tabular}{|c|c|c|c|c|c|c|}
\hline \multicolumn{2}{|c|}{$\begin{array}{l}\text { Universitat Autònoma de } \\
\text { Barcelona }\end{array}$} & \multirow{2}{*}{$\begin{array}{c}\mathbf{N} \\
\text { profes. } \\
49\end{array}$} & \multirow{2}{*}{$\begin{array}{c}\begin{array}{c}\mathbf{N} \\
\text { contesta- } \\
\text { dos }\end{array} \\
12 \\
24,49 \% \\
\end{array}$} & \multirow{2}{*}{$\begin{array}{l}\begin{array}{c}\text { Universitat Politècnica } \\
\text { de Catalunya }\end{array} \\
\text { Física e Ingeniería Nu- } \\
\text { clear }\end{array}$} & \multirow{2}{*}{$\begin{array}{c}\text { N } \\
\text { profes. }\end{array}$} & \multirow{2}{*}{$\begin{array}{c}\begin{array}{c}\mathbf{N} \\
\text { contesta- } \\
\text { dos }\end{array} \\
17 \\
17 \% \\
\end{array}$} \\
\hline \multirow{3}{*}{$\begin{array}{l}\frac{\text { Ciencias Ex- }}{\text { perimentales y }} \\
\text { Tecnologías: }\end{array}$} & Ingeniería Química & & & & & \\
\hline & Matemáticas & 98 & $\begin{array}{c}10 \\
10,2 \% \\
\end{array}$ & Ingeniería Electrónica & 137 & $\begin{array}{c}19 \\
13,9 \% \\
\end{array}$ \\
\hline & Química & 108 & $\begin{array}{c}38 \\
35,2 \%\end{array}$ & Matemática Aplicada IV & 60 & $\begin{array}{c}0 \\
0 \%\end{array}$ \\
\hline \multirow{3}{*}{$\begin{array}{l}\text { Ciencias de la } \\
\underline{\text { Salud: }}\end{array}$} & $\begin{array}{l}\text { Ciencias } \\
\text { Morfológicas }\end{array}$ & 42 & $\begin{array}{c}18 \\
42,8 \% \\
\end{array}$ & Ingeniería Telemática & 45 & $\begin{array}{c}0 \\
0 \% \\
\end{array}$ \\
\hline & $\begin{array}{l}\text { Farmacologia y } \\
\text { Terapéutica }\end{array}$ & 56 & $\begin{array}{c}7 \\
12,5 \% \\
\end{array}$ & $\begin{array}{l}\text { Ingeniería Hidráulica, } \\
\text { Marítima y Ambiental }\end{array}$ & 30 & $\begin{array}{c}0 \\
0 \% \\
\end{array}$ \\
\hline & $\begin{array}{l}\text { Psicología de la } \\
\text { Salud y Psicologia } \\
\text { Social }\end{array}$ & 57 & $\begin{array}{c}13 \\
22,8 \%\end{array}$ & $\begin{array}{l}\text { Ingeniería de Sistemas, } \\
\text { Automática e Informáti- } \\
\text { ca Industrial }\end{array}$ & 46 & $\begin{array}{c}15 \\
32,6 \%\end{array}$ \\
\hline \multirow{3}{*}{$\begin{array}{l}\text { Ciencias So- } \\
\text { ciales: }\end{array}$} & $\begin{array}{l}\text { Economía de la Em- } \\
\text { presa }\end{array}$ & 146 & $\begin{array}{c}9 \\
6,2 \% \\
\end{array}$ & $\begin{array}{l}\text { Organización de Empre- } \\
\text { sas }\end{array}$ & 106 & $\begin{array}{c}9 \\
8,49 \% \\
\end{array}$ \\
\hline & Pedagogía Aplicada & 49 & $\begin{array}{c}14 \\
28,6 \% \\
\end{array}$ & Óptica y Optometría & 53 & $\begin{array}{c}14 \\
26,4 \% \\
\end{array}$ \\
\hline & $\begin{array}{l}\text { Periodismo y } \\
\text { Ciencias de la } \\
\text { Comunicación } \\
\end{array}$ & 74 & $\begin{array}{c}26 \\
35,1 \%\end{array}$ & $\begin{array}{l}\text { Construcciones Arqui- } \\
\text { tectónicas II }\end{array}$ & 37 & $\begin{array}{c}0 \\
0 \%\end{array}$ \\
\hline \multirow{3}{*}{$\begin{array}{l}\text { Ciencias } \\
\text { Humanas: }\end{array}$} & Filología Catalana & 77 & $\begin{array}{c}16 \\
20,8 \% \\
\end{array}$ & Matemática Aplicada II & 61 & $\begin{array}{c}0 \\
0 \% \\
\end{array}$ \\
\hline & $\begin{array}{l}\text { Historia Moderna y } \\
\text { Contemporanea }\end{array}$ & 48 & $\begin{array}{c}0 \\
0 \% \\
\end{array}$ & $\begin{array}{l}\text { Ciencia e Ingeniería } \\
\text { Náuticas }\end{array}$ & 27 & $\begin{array}{c}6 \\
22,2 \% \\
\end{array}$ \\
\hline & $\begin{array}{l}\text { Traducción e } \\
\text { Interpretación }\end{array}$ & 87 & $\begin{array}{c}16 \\
33,3 \%\end{array}$ & $\begin{array}{l}\text { Resistencia de Materia- } \\
\text { les y Estructuras en } \\
\text { Ingeniería }\end{array}$ & 49 & $\begin{array}{c}4 \\
8,2 \%\end{array}$ \\
\hline Total & UAB & 891 & $\begin{array}{c}168 \\
18,8 \%\end{array}$ & UPC & 751 & $\begin{array}{c}85 \\
11,31 \%\end{array}$ \\
\hline
\end{tabular}

En conjunto han contestado un $66,4 \%$ de profesorado de la UAB y un $33,6 \%$ de la UPC. Distribuidos desde el punto de vista del género, el $66,8 \%$ son hombres y el 33,2\% mujeres. En la distribución por edades, el 8\% son profesores menores de 30 años, el 35,7\% tienen entre 30 y 40 años, casi el $48 \%$ tiene de 41 a 50 años y un 8,4\% tiene más de 50 .

Con respecto a la titulación, los profesores doctores representan un 70\% de la población. 
La distribución de acuerdo a la modalidad contractual indica que los profesores titulares representan la población con un porcentaje más alto de cuestionarios contestados (casi un $48 \%$ ), seguido de los profesores asociados a tiempo parcial y a tiempo completo (un $30 \%$ ) y de los catedráticos (un 13\%). La baja representación de los becarios o ayudantes pre-doctorales (1\%) se justifica por el hecho que muy pocos han ejercido la docencia.

En cuanto a la titulación, el 47,8\% de los encuestados da clases en el área de ciencias experimentales y tecnologías - justo es decir que todos los profesores de la UPC excepto los del Departamento de Óptica y Optometría, imparten docencia en esta área. El resto imparte en ciencias sociales (un 19,8\%), ciencias de la salud (un 19\%) y ciencias humanas (un 15\%).

La media de todos los profesores encuestados es de 15 años de experiencia docente a la universidad: un $8,8 \%$ se pueden considerar profesores noveles (menos de 4 años de experiencia), un $30 \%$ tiene de 4 a 10 años de experiencia y el 60\% tiene 10 años o más (de los cuales un 16,7\% lleva más de 25 años en la universidad).

Casi un $40 \%$ de los profesores tienen o han tenido experiencia docente en el ámbito no universitario. Un 46,5\% no ha tenido más de 5 años pero hay un $25,7 \%$ que tiene más de 10.

Finalmente, se destaca que un $23,7 \%$ de los encuestados manifiesta haber realizado algún tipo de formación inicial (un 55,5\% de la UAB y un $44,5 \%$ de la UPC). Mayoritariamente, los profesores han seguido el curso de formación del profesor novel organizado por el Instituto de Ciencias de la Educación de la universidad correspondiente (un 18,6\%); un 2,4\% han realizado algún curso de preparación para la docencia de la facultad y un $5,5 \%$ ha hecho algún taller de formación didáctica.
En relación al porcentaje de tiempo que el profesorado destina a cada una de las principales funciones universitarias, docencia, investigación y gestión, la media de los encuestados dedica un $47,7 \%$ de su tiempo a la docencia, un $37,1 \%$ a la investigación y un $17,8 \%$ a la gestión. Esta cifra indica que la investigación aparece en segundo lugar tras la docencia.

Además del análisis de las medias generales y las frecuencias de los ítems y de las preguntas abiertas, hemos procedido con los estudios siguientes:

A. Análisis de varianza para comparar las medias de los ítems donde aparecen diferencias significativas en función de las variables del cuestionario,

B. Estudio de las preguntas abiertas en relación con las concepciones sobre enseñar y aprender y enfoques docentes

y con técnicas de reducción de la información mediante:

C. Análisis factoriales para identificar un conjunto de factores que explican las relaciones existentes entre las variables que conforman los ítems del cuestionario.

A. De la comparación de medias en función de las variables del cuestionario:

De las diferencias significativas halladas podemos extraer los siguientes resultados. En primer lugar, a mayor edad y años de experiencia docente universitaria, mayor protagonismo en la clase. Este docente principalmente basa su docencia en la transmisión del contenido y en su conocimiento sobre la materia y procura abordar todo el programa. Cree que la docencia en la universidad debe partir de la base que los estudiantes han de aprender aquello que el profesor enseña y planifica la asignatura pensando que sus estudiantes tienen pocos conocimientos de la materia. Concretamente, no cree que la experiencia de los estudiantes sea tan importante como la suya y opina que su experiencia profesional es esencial para ayudarles a 
entender el contenido de la asignatura. Este perfil se identifica más con el género masculino que con el femenino.

El profesor joven, con menos experiencia $\mathrm{y}$, sobre todo, el profesorado asociado, manifiesta que tiene lagunas de conocimiento de la materia que imparte y requiere las sugerencias de los profesores más experimentados. Habitualmente mantiene una relación próxima con los estudiantes y piensa que pueden hacer importantes aportaciones a través de sus experiencias vividas.

Los profesores de ciencias humanas y ciencias sociales son más partidarios de conversar con los estudiantes, preguntar dificultades, utilizar metodologías diversas para comprender como se están desarrollando sus aprendizajes y procuran que los estudiantes generen sus propias ideas. Los profesores de ciencias experimentales y ciencias de la salud están menos de acuerdo en discutir y pactar el contenido y creen que los estudiantes contribuyen poco en clase por falta de experiencia profesional. Los últimos manifiestan que su experiencia profesional es esencial para ayudarles a entender el contenido de la asignatura.

Los profesores que imparten más créditos anuales de docencia, por lo tanto destinan más tiempo a la docencia, se preocupan más por los aprendizajes de los estudiantes, confían más en la experiencia de los estudiantes intentándola relacionar con la asignatura y tutorizan más trabajos fuera de clase.

B. Del estudio de las preguntas abiertas para comparar las medias en función de las concepciones docentes

Para realizar esta comparación de medias, mediante el análisis de varianza, sólo se han considerado aquellas preguntas abiertas con más de un $10 \%$ de respuestas.

Analizando las respuestas a la primera pregunta abierta sobre la enseñanza y los ítems del cuestionario, encontramos que los docen- tes que entienden la enseñanza como la transformación del conocimiento presentan diferencias significativas con los que la conciben como una transmisión cultural con respecto a los aspectos siguientes: presentan más interés en querer conocer qué y como aprenden los estudiantes (ítem 4), utilizan una metodología que les da información sobre como aprenden los estudiantes (ítem 37), preguntan a los estudiantes sobre sus experiencias vividas para poder relacionarlas con la asignatura (ítem 40), no utilizan métodos y recursos de otros docentes (ítem 42), comprueban el que aprenden los estudiantes a lo largo del semestre (ítem 52), y hablan con los estudiantes sobre aspectos de la materia que estudian, especialmente las dificultades que comportan (ítem 55).

En relación con la segunda pregunta abierta sobre el aprendizaje, encontramos diferencias significativas entre los profesores que conciben el aprendizaje como desarrollo de destrezas y los que lo definen como la adquisición de conocimientos. Los primeros manifiestan estar más de acuerdo que enseñan a los estudiantes a reestructurar sus conocimientos para entender la asignatura desde diferentes perspectivas (ítem 28) y comprueban lo que van aprendiendo a lo largo del semestre (ítem 52).

A diferencia de los docentes que entienden el aprendizaje como la adquisición de conocimientos, los profesores que lo han precisado como transformación o cambio conceptual utilizan una metodología que les da información de como aprenden los estudiantes (ítem 37), conversan con los estudiantes sobre aspectos de la materia que estudian (ítem 55) y procuran que los estudiantes generen sus propias ideas y sus propios apuntes (ítem 58).

Con respecto al estilo docente, aquel profesor que lo describe como transmisivo, a diferencia del reflexivo, puntúa alto en el ítem 44 (doy clases magistrales porque tengo muchos estudiantes) y, a diferencia del profesor con 
un estilo interactivo, el profesor expositivo manifiesta que los estudiantes se muestran pasivos en clase, y sólo toman nota de lo que se explica (ítem 59). El profesor reflexivo, por otro lado, conversa en clase sobre aspectos de la materia que conllevan dificultades (ítem 55).

\section{Del análisis factorial}

El análisis factorial es una técnica estadística paramétrica que nos permite identificar un conjunto de factores que expliquen las relaciones existentes entre el conjunto de las 60 variables que conforman los ítems de nuestro instrumento. Siguiendo Bisquerra (1989), el análisis factorial es un tipo de método denominado reductivo puesto que "estudia las interdependencias entre todas las variables con el objetivo de reducir al mínimo el número de variables necesarias para describir la información relevante contenida en las observaciones.” (p.9).

Se ha llevado a cabo un análisis factorial de componentes principales con carácter exploratorio mediante el programa FACTOR de SPPS con objeto de contrastar la correspondencia entre la estructura interna teórica del instrumento con la proporcionada por el análisis factorial. Para proceder a la identificación de factores a partir del análisis factorial hemos considerado oportuno utilizar dos procedimientos de análisis:

- En primer lugar, extraer todos los posibles factores resultados de la interacción del conjunto de variables que conforman los ítems del instrumento. En el primer intento, han aparecido 18 factores, con valores propios superiores a 1 , que hemos considerado excesivos.

- A continuación, hemos pedido sólo 3 factores, los de mayor peso y también se ha realizado una rotación ortogonal (Varimax) para ver la mejor distribución de los ítems en estos tres factores. La solución final está a la matriz de componentes rotados, donde se puede ver la contribución de cada ítem a cada uno de los factores.

El resultado es un primer factor correspondiente al enfoque docente centrado en el aprendizaje del estudiante, un segundo factor representando un enfoque docente centrado en la transmisión de conocimiento y un tercer factor con un enfoque centrado en el profesor.

Factor 1. Enfoque docente centrado en el estudiante y su aprendizaje

Todas las variables relacionadas con el aprendizaje de los estudiantes presentan saturaciones altas (ítems $1,4,7,10,13$ ) denotando una preocupación por acercarse, comprender y satisfacer las necesidades de los estudiantes (ítem 10), y se incorporan dos ítems del enfoque centrado en el profesor, referentes a una metodología condicionada por el número de estudiantes (ítem 44) y, consiguientemente a una relación distante entre ambos (ítem 58).

De la composición de los ítems de este factor se desprende que hay una predisposición a centrar la docencia en los aprendizajes de los estudiantes y a la reflexión. Este factor recoge información sobre el interés y la tendencia de los profesores reflexivos a cuestionar las ideas de los estudiantes y enseñar a reestructurar sus conocimientos para poder comprender la asignatura desde diferentes puntos de vista.

Factor 2. Enfoque docente centrado en el profesor y su enseñanza

Las saturaciones más altas corresponden a los ítems relacionados con el enfoque docente del profesor que centra principalmente su docencia en la transmisión cultural.

Este factor reúne información sobre actitudes del profesor y características docentes. Le preocupa qué pensarán de él o ella (ítem 9) pese a mostrarse confiado en su enseñanza (ítems 17 y 20). Su docencia se caracteriza por la transmisión casi unidireccional del 
contenido de la materia, trabajar un buen libro de texto, intentar abordar todo el programa con el objetivo de que los estudiantes adquieran los principales conceptos y acaben el curso bien documentados (ítems 5, 8, 11, 14 y 23). La experiencia y su conocimiento de la materia es esencial para llevar a cabo la asignatura; el profesor ha de estar preparado para cualquier pregunta y los estudiantes han de aprender aquello que el profesor enseña (ítems 26, 29 y 35). Este factor nos indica que el profesor parte del supuesto que los estudiantes no conocen nada de la asignatura y, consiguientemente, la evaluación se centrará en comprobar si han comprendido aquello explicado (35, 38, 41 y 50).

Este factor recoge información sobre la preocupación de los docentes respecto de la transmisión y adquisición de los principales conceptos y conocimientos por parte del estudiante, característica propia del estilo docente expositivo. El denominador común de todos los ítems es una demostración de dominio del conocimiento y de destrezas discursivas por parte del profesor tanto en la planificación de la materia como en su impartición.

Factor 3. Enfoque docente centrado en sí mismo.

Las saturaciones más altas corresponden a los ítems relacionados con el grado de conocimiento de la materia (ítems 3, 6, 15, 24), con el miedo a hacerlo mal (ítems 12, 27, 30, 36, 54), con exhibir inseguridad a clase (ítems 15 y 54), con la supeditación de las decisiones docentes a criterios de profesores más experimentados (ítems 33 y 51) y con la relación próxima con los estudiantes (ítems 21, 57 y 60).

Este factor nos muestra un perfil de profesor recientemente iniciado a la docencia, con poco criterio propio con respecto al diseño y desarrollo de la materia, involucrado con algunos problemas de los estudiantes. Se pone de manifiesto que los profesores con este enfoque no dominan satisfactoriamente la asignatura, se muestran inseguros e intranquilos y necesitan el apoyo de personas experimentadas.

\section{Análisis cualitativo: preguntas abiertas del cuestionario y entrevistas}

El cuestionario incluye preguntas abiertas que nos deben permitir contrastar las respuestas del profesorado con las respuestas de los ítems estandarizados. Las respuestas de los ítems cuantitativos indican que el 15,3\% del profesorado "utilizan una metodología que me da información de como aprenden los estudiantes” (ítem 37). ¿Pero a qué metodología se refieren? ¿Cómo la describen con sus propias palabras? Las preguntas abiertas ofrecen profundidad, detalle y significado a un nivel muy personal de la experiencia (Patton, 1990).

La intención con las preguntas abiertas del cuestionario es obtener evidencias más subjetivas de las concepciones y del enfoque docente del profesor y comprobar la coherencia con los ítems del cuestionario. Nos interesa conocer si lo que dicen que hacen (manifestación, expresión), es coherente con sus visiones acerca de la docencia (concepciones). Se da el caso de docentes que se muestran totalmente de acuerdo con el enunciado "Enseño los estudiantes a reestructurar sus conocimientos para entender la asignatura desde varias perspectivas" y (ítem 28), definen su enseñanza como "una transmisión de contenidos mediante clases magistrales" (cuestionario 38).

Para organizar las respuestas acerca de los enfoques y concepciones docentes se han utilizado las categorías identificadas en el esquema de Ramsden (1993) y de Prosser y Trigwell (1999). A la pregunta A. "Entiendo que enseñar en la universidad significa..." , las respuestas se han agrupado de la forma siguiente:

\section{- Enseñanza como transmisión cultural:}

Dentro de esta categoría se aglutinan aquellas respuestas que definen la enseñanza co- 
mo la transmisión de un cuerpo de conocimiento disciplinario. Incluye las respuestas que hacen referencia a la transmisión o comunicación de contenidos conceptuales, procedimentales y actitudinales que se expresan cómo:

- la transmisión de información o de conceptos de un programa,

- la transmisión del conocimiento del profesor,

- la transmisión de una manera de hacer o de ser,

- la ayuda a los estudiantes a adquirir los conceptos del programa,

- la ayuda a los estudiantes a adquirir los conocimientos del profesor.

A continuación mostramos algunos ejemplos:

- "Transmitir al alumnado el contenido de la materia, filtrada por mis conocimientos, mis reflexiones y la investigación sobre el tema, en el marco de una estructura.” (c. 97)

- "Transmitir una serie de conocimientos teóricos y prácticos útiles para los futuros profesionales.” (c.148)

- "El contenido del curso y su plena asunción por parte del alumnado.” (c.156)

- "Transmitir unos conocimientos para que sean bien asimilados por quien los reciba, de manera que lleguen progresivamente a desarrollarlos por ellos mismos.” (c.129)

- Enseñanza como entrenamiento de habilidades:

Esta categoría engloba las respuestas que definen la enseñanza como la ayuda o el entrenamiento de los estudiantes a desarrollar destrezas y capacidades formales simples y complejas como la resolución de problemas, la reflexión, el análisis crítico de hechos y situaciones... como la organización de la actividad del estudiante o la articulación de técnicas diseñadas a asegurar que el estudiante aprende.
- "Fomentar una capacidad de búsqueda de la información, una capacitad de análisis de la información, una capacidad de definición de problemas, una capacidad de proponer resoluciones de problemas, de contrastar resultados, y de corregir políticas en consecuencia.” (c.11)

- "Enseñar a pensar, enseñar a buscar la información, enseñar a comprenderla, enseñar a seleccionarla, enseñar a tratar pacientes y compañeros, enseñar a no obedecer.” (c.118)

- "Hacer que los estudiantes sean capaces de resolver problemas de la materia en función del estudio, la reflexión y la investigación y a través de las prácticas.” (c.121)

- "Transmitir los conocimientos y desarrollar las capacidades necesarias para que el estudiante pueda desarrollar el que la sociedad le pida como titulado.” (c.152)

\section{- Enseñanza como producción de cambios conceptuales:}

La enseñanza bajo esta categoría se entiende como la ayuda a los estudiantes a cambiar sus propias concepciones y su comprensión de la materia, a transformar sus creencias y pensamientos a partir de la movilización de los esquemas existentes de su pensamiento.

- “Enseñar a pensar por un mismo. Fomentar actitudes de crítica intelectual, romper dogmatismos y desincentivar la obediencia intelectual acrítica.” (c.115)

- “Enseñar a reflexionar, a pensar y a resolver los problemas que se presentarán en la vida profesional. Dar elementos para que los alumnos reflexionen con sentido crítico todo el que nos rodea.” (c.102)

- "Comunicar unos conocimientos desde un punto de vista crítico y con perspectiva de conjunto dejando un margen para varios enfoques, de una manera sistemática y sobre todo capacitar al alumno para el aprendizaje autónomo y crítico.” (c.82) 
- "Ayudar a los estudiantes a cambiar sus concepciones sobre la materia, a desarrollar sus capacidades intelectuales para llegar a ser excelentes profesionales.” (c.62)

Sobre las concepciones de enseñanza, un $23,7 \%$ de los profesores concibe enseñar como transmitir conocimiento o contenidos, un 33,6\% como el desarrollo de habilidades y un $17 \%$ como la producción de cambios conceptuales en el estudiante.

En relación a las respuestas al ítem B: "Entiendo que aprender en la universidad significa...” éstas se pueden agrupar en:

- Aprendizaje como adquisición de conoci$\underline{\text { miento: }}$

Incluye respuestas que consideran el aprendizaje como la adquisición de información, de conceptos, del conocimiento del profesor.

- “Lograr conceptos.” (c.227)

- "Adquirir unos conocimientos, sin definir la vía (de los compañeros, de los profesores, de los libros)” (c.141)

- "Adquirir conocimientos sobre una materia.” (c.114)

- "Adquirir informaciones en marcos comprensibles e inteligibles.” (c.107)

\section{- Aprendizaje como desarrollo de destrezas:}

Bajo esta categoría se incluyen todas aquellas posturas que definen el aprendizaje como un proceso de desarrollo de habilidades, no de contenidos. Se asume la concepción de que el aprendizaje se da por interacción y se utilizan técnicas para promover la discusión, prácticas para relacionar el conocimiento teórico con la experiencia del estudiante...

- "Integrar los conocimientos para decidir qué hacer en una situación concreta, como hacerlo, cuando hacerlo, por qué y para qué hacerlo.” (c.39)

- "Saber buscar dónde haga falta la solución a los interrogantes. Adquirir los co- nocimientos adecuados a la materia." (c.88)

- “Conocer la metodología por acceder al conocimiento y a la vez ir disponiendo de los recursos pertinentes para lograr este objetivo.” (c.106)

- "Captar, replantear, asimilar lo explicado para construir un nuevo saber.” (c.117)

- Aprendizaje como transformación, cambio, desarrollo conceptual:

Esta categoría entiende el aprendizaje como la construcción del conocimiento a partir de la aplicación y modificación de las propias ideas. Representa un cambio de las concepciones previas y un desarrollo de nuevas maneras de interpretar la realidad.

- "Reflexionar sobre los diversos paradigmas científicos e ideológicos presentes en las ciencias sociales y humanas. " (c.115)

- "Saber tratar la información relacionándola con marcos conceptuales y saberla contextualizar.” (с.66)

- "Integrar un marco amplio de conocimientos, habilidades y valores profesionales para afrontar de manera autónoma los retos educativos.” (c.60)

De manera similar se presentan los resultados respecto de las concepciones de aprendizaje: un 29,2\% de los encuestados entiende aprender como adquirir conocimientos, el $38,7 \%$ lo concibe como desarrollar habilidades $\mathrm{y}$, finalmente el 16,6\% responde que aprendizaje significa transformación, cambio o producción conceptual. Los porcentajes de respuesta para cada una de las concepciones de enseñanza y aprendizaje se corresponden con las del cuestionario.

En el caso de las respuestas al ítem C. "Aspectos de la docencia que han cambiado”, principalmente se destacan:

- Mejor organización del programa y de la clase 
"Me he preocupado cada vez más por la organización y la planificación.” (c.68)

"Definir unos objetivos más claros a los problemas o explicaciones.” (c.48)

- Mayor adaptación del conocimiento a las necesidades del mundo real

"He tratado de ser un profesor cosmopolita abierto a las aportaciones extranjeras.” (c.92)

"De más académico a más centrado en problemas reales.” (c.66)

- Más conocimiento del contenido, más $\underline{\text { dominio }}$

"He madurado planteamientos y creo que los transmito cono más serenidad.” (c.107)

- Más adaptación al nivel de exigencia de los estudiantes (c. 35)

"Creo que he readaptado los contenidos a las necesidades 'reales' de los alumnos." (c.182)

- Más dinamismo (menos lecciones magistrales)

"Cada vez valoro más el trabajo experimental frente al teórico. Cada vez creo menos en el valor de las clases expositivas/magistrales que usamos en la escuela." (q.182)

\section{Entrevistas}

Los resultados de las entrevistas nos permiten afirmar la existencia de diferencias en la manera en que los profesores experimentan y conciben la docencia. La mayoría son consecuencia de la situación de enseñanza experimentada anteriormente, pero también de sus concepciones docentes y el entorno académico y disciplinar.

Los profesores noveles (con menos de dos años de experiencia docente) conciben enseñar como "transmitir conocimientos para que sean útiles a los estudiantes" (O.A.), "entender las cosas para saber aplicarlas después, relacionarlas, saber razonar...Es diferente que enseñar en el instituto, no se debe memorizar todo" (A.N.); o bien se entiende como intentar ayudar, resolver dudas, motivar a los estudiantes hacia el aprendizaje.

Los profesores más centrados en su enseñanza definen enseñar a la universidad como transmitir conocimiento "con motivación personal y con facilidad para que el estudiante pueda participar en el contenido de la materia del programa" (J.M.F.). Para otras no solamente se trata de transmitir contenidos, sino también "intentar transmitir una manera de hacer, de entender las cosas, de actuar, y adquirir conceptos y aptitudes" (C.P.).

En general el objetivo es la formación del estudiante: "ayudar a los estudiantes a aprender, básicamente" (J.B.), "enseñar a aprender” (E.P.), “enseñar a pensar, transmitir un estilo, un talante” (M.J.E).

Desde el punto de vista de la enseñanza como contribuir a desarrollar y cambiar concepciones en los estudiantes, hay quien opina que dicha concepción de la enseñanza puede variar según la asignatura. H.T. concibe la enseñanza de manera diferente según la asignatura sea teórica o se trate de prácticas: "Yo creo que hay diferentes asignaturas en un plan de estudios que cumplen diferentes funciones en la formación de los alumnos... depende de qué asignatura me toque, yo pienso que es una cosa u otra. Para una asignatura teórica supone...tener una perspectiva desde otro punto de vista, en el caso de las asignaturas de practicum, el objetivo es conseguir “...un cambio personal... Supone un cambio de mentalidad respecto de su propia futura práctica (de los estudiantes).” (H.T.).

También es visto como la preparación del estudiante para afrontar los retos del mundo laboral: "formación en el ámbito personal de los alumnos, orientada a desarrollarse en el mundo laboral; formación abierta, generalista” (M.P.); "enseñar a los alumnos una 
profesión, la ingeniería; darles los conocimientos prácticos para que los puedan aplicar y desarrollarse en una profesión" (P.C.); "la formación integral de la persona, una formación técnica, humana... en definitiva global” (A.R.S); "convertirse en un humanista, ser capaz de entender qué pasa en la vida, desde el punto de vista de la cultura" (F.E.).

El aprendizaje es visto por parte de los profesores más centrados en su enseñanza, como "la asimilación de conocimientos" (J.M.F.), "aprender los fundamentos científicos de los conocimientos, pero sobre todo la aplicación práctica. Adquirir conocimientos teóricos y prácticos” (P.C.).

Es además de adquisición de conocimientos, una preparación para adquirir habilidades: Se espera "que tengan las ideas de los conceptos generales, es una universidad técnica, la práctica en el uso de las máquinas y que aprendan técnicas que permitan construir cosas" (O.A). Desde esta orientación más técnica definen el aprendizaje como "desarrollarse ante un problema y saberlo resolver” (E.P.).

Aquellos profesores que lo conciben desde el punto de vista de la transformación del conocimiento apuntan que aprender es "enfrentarse a nuevas situaciones, nuevos conocimientos y aprenderlas” (J.B.); “desarrollar aptitudes para buscar recursos, relacionar conceptos, conseguir una mentalidad abierta en situaciones diferentes para aplicar conocimientos básicos o saber dónde encontrarlos” (M.P.); “adquirir todo lo que te llega del exterior de diferentes maneras; crear nuevas ideas y nuevos conocimientos" (CP.); "seria lograr este cambio de concepción y adquirir hábitos reflexivos respecto de la propia práctica" (H.T). Los humanistas lo entienden como "adquirir cultura, conseguir que el alumno sea capaz de situarse, transitar con habilidad y que tenga los conocimientos e instrumentos por mover se en este mundo, con naturalidad" (F.E.).
Respecto del estilo docente, la mayoría de los profesores entrevistados lo caracterizan como una combinación de clases teóricas y prácticas: "estilo ágil, expositivo con actividades prácticas participativas” (M.J.E.), "hago desde clases magistrales, teóricas hasta clases prácticas” (P.C); “clases variadas, según la asignatura: algunas de teóricas, otras de muy prácticas. Cada clase es diferente. Son en general clases muy interactivas" (A.N.); "intento que aprendan una práctica y la teoría que lo acompaña. Doy clases teóricas magistrales y prácticas por resolver dudas" (O.A.). "Soy polivalente; al lado de una sesión muy dinámica de participación con debate activo por parte de los alumnos, otra de teórica, de magistral” (J.M.F.).

Hay quien puntualiza "siempre he dado clases expositivas, pero en los últimos años he intentado imponer un contenido más práctico, más actividades, más dinamismo, por razón de la propia maduración” (J.B.) "Las clases magistrales son el elemento central. También aporto libros como imágenes por atender las preguntas que surgen. Los alumnos también plantean cuestiones y aportan cosas, pero pocas veces” (F.E.).

En síntesis podemos decir que los entrevistados conciben la enseñanza: como la transmisión de los conocimientos de los profesores, como una ayuda a desarrollarse en el mundo laboral, y como una oferta de formación integral, técnica y humana. El aprendizaje es entendido como la asimilación de conocimientos, el desarrollo de habilidades (la resolución de problemas, las aptitudes por buscar recursos...), y como la creación de nuevas ideas y nuevos conocimientos.

El estilo docente que describen también es variado y tiene en común que la mayoría de profesores combina las clases teóricas con las clases prácticas intentando ser interactivo y dinámico. El profesorado manifiesta que ha cambiado a lo largo de su trayectoria universitaria, excepto los más noveles y un entre- 
vistado que mantiene que han cambiado los contenidos pero no el método. La docencia, en general, procura ayudar al estudiante a desarrollar sus propias concepciones sobre la realidad y su participación se considera clave para conseguirlo.

\section{Discusión}

Gran parte de las investigaciones realizadas por académicos anglosajones sobre las concepciones y enfoques docentes del profesorado universitario se han desarrollado desde la perspectiva fenomenográfica (experiencial o semiantropológica). El término acuñado por Marton y Booth (1997), pretende conocer las formas, cualitativamente diferentes, en que las personas experimentan, conceptualizan, perciben y comprenden el mundo que les rodea. Los estudios fenomenográficos realizados en la universidad pretenden descubrir las formas de comprensión que el profesorado universitario tiene de fenómenos específicos, como su experiencia docente, para encuadrarlos dentro de categorías conceptuales.

Tomando de referencia los estudios fenomenográficos (Dall’Alba, 1991, Pratt, 1992; Samuelowicz y Bain; 1992; Prosser y Trigwell, 1999 y Åkerlind, 2003), pero desde un enfoque metodológico mixto, nuestro análisis cuantitativo y cualitativo también ofrece una gran variabilidad de evidencias sobre como el profesorado universitario comprende y percibe sus experiencias y expresa sus concepciones sobre docencia.

Las creencias del profesorado revelan una manera de practicar la docencia. Así, de acuerdo con Trigwell y Prosser (1999), aquellos docentes que creen que enseñar es transmitir información, describen su estilo docente como expositivo, y los que opinan que enseñar es cambiar las concepciones de los estudiantes, suelen mantener un estilo docente centrado en la reflexión y el debate con los estudiantes, a partir de sus propias experiencias y conocimiento.
Para Marcelo (1987) hay profesores que tienen conflictos entre sus creencias y su conducta en clase, en el sentido que su conducta docente no se corresponde con sus creencias y viceversa. Parece que durante los primeros años de docencia las creencias sobre enseñar y la conducta en clase de los profesores pueden entrar en conflicto. No obstante, una vez los profesores consolidan sus creencias, son éstas las que definitivamente dirigen y controlan su conducta.

Concretamente, de nuestro estudio se derivan respuestas que corroboran la teoría de Ramsden (1993) por la que la enseñanza puede ser concebida como: a) la transmisión de conocimiento o de información, b) el desarrollo de destrezas o habilidades en el estudiante y c) el cambio en la comprensión de la materia y el desarrollo de nuevas concepciones. En la definición de enseñanza se reitera de manera constante la idea que enseñar es también entusiasmar, estimular y motivar a los estudiantes a aprender. Y el aprendizaje es definido como: a) la adquisición del conocimiento del profesor, b) la adquisición de técnicas y c) la transformación del conocimiento.

Las categorías descritas se ordenan de menor a mayor comprensión de la docencia (Dall'Alba, 1991), son progresivas en el sentido de que la tercera incluye la segunda y primera visión de la docencia (Ramsden, 1993) y la relación entre ellas puede, por lo tanto, explicarse desde una jerarquía de inclusividad (Åkerlind, 2007).

Lo hemos comprobado con las respuestas a las preguntas abiertas: aquellos profesores que han definido enseñar como transmitir conocimientos y aprender cómo adquirirlos, en general, presentan un estilo docente claramente expositivo, caracterizado por las clases magistrales. A estos docentes los preocupa principalmente que la asignatura esté bien estructurada y procuran que su transmisión sea clara; transmiten únicamente aquella información que es motivo de evaluación y 
procuran que los estudiantes acaben el curso bien documentados. Irónicamente, lamentan la pasividad de los estudiantes.

El profesorado que concibe la docencia como un desarrollo de destrezas presenta un estilo interactivo, fruto de la combinación de sesiones teóricas y prácticas y también ayuda a los estudiantes a reestructurar sus conocimientos para entender la asignatura desde varias perspectivas. Este es el estilo que conforma la mayoría de profesores entrevistados.

Entender la docencia como la transformación del conocimiento implica utilizar una metodología que dé información de cómo y qué aprenden los estudiantes, conocer sus experiencias para poder relacionarlas con la asignatura, utilizar métodos y recursos propios, comprobar lo que van aprendiendo a lo largo del semestre y conversar con ellos sobre las dificultades de la asignatura. La orientación docente centrada en los estudiantes y sus aprendizajes tiene lógicamente relación directa con la concepción de enseñanza vinculada a la producción de cambios conceptuales; a la concepción de aprendizaje como transformación conceptual y al estilo docente reflexivo.

De los distintos estilos docentes que exhibe el profesorado universitario (estilo expositivo, el interactivo y el reflexivo), el expositivo es el que se considera menos eficaz para el aprendizaje de los estudiantes; el profesor con este perfil muestra un menor nivel de experticia pedagógica.

Como se observa en algunas respuestas de los entrevistados, el enfoque docente es relacional o situacional (Prosser y Trigwell, 1999), no es una característica relativamente estable de un académico. Es decir, puede cambiar según las percepciones del profesor sobre su situación profesional docente y según el contexto de su docencia (curso, asignatura que imparte, número de alumnos, cultura disciplinar, etc.). Sin embargo, siempre hay un estilo que predomina, un estilo propio que a la larga acaba siendo consistente y se mantiene más o menos constante en diferentes contextos y disciplinas.

Lo que encontramos en la práctica, a partir de nuestros resultados, es una fusión de estilos con el predominio del estilo interactivo, dando lugar a combinaciones de estilos expositivo-interactivo o interactivo-reflexivo, como lo demuestra el análisis factorial y las entrevistas.

En nuestra investigación vemos que el estilo docente centrado en el profesor se da en aquellos académicos con mayor experiencia y edad, pero no podemos confirmar que en conjunto los tres estilos docentes guarden relación con la categoría profesional o la titulación, es más cada profesor lo desarrolla a partir de modelos docentes conocidos, el conocimiento, la experiencia y la reflexión docente.

A modo de ejemplo, nuestro estudio identifica la existencia de profesores jóvenes, con relativamente poca experiencia docente en la universidad, con un contrato como profesor en formación y de ámbitos de conocimiento diversos que mantienen un enfoque centrado en el estudiante. Su desarrollo como docente se ha forjado a partir de modelos de académicos con una especial atención al estudiante, por la adquisición de conocimiento pedagógico y la reflexión independiente o compartida (entre iguales, supervisores, expertos) sobre aspectos relacionados con la docencia.

Aunque el tipo de docencia que practican los profesores no depende de la experiencia previa, la categoría profesional o la titulación, el área de conocimiento a la que pertenecen, la formación pedagógica o el número de créditos anuales de docencia sí son factores determinantes. Podemos afirmar, a partir de los resultados del cuestionario, que el profesorado de ciencias experimentales y tecnologías presentan una orientación docente más centrada en la enseñanza, y también que los docentes con formación pedagógica y que destinan más horas a la docencia que a la 
investigación adoptan una orientación más centrada en el aprendizaje de los estudiantes.

Aún así, decir que las diferentes maneras de comprender la docencia sean más comunes entre los profesores de unas áreas que de otras es provocativo. Sería injusto decir que las orientaciones van asociadas a la naturaleza de las materias o que la organización social de las culturas disciplinarias determina la teoría que sus profesores utilizan. Es más probable decir que encontraremos profesores y cursos que ilustran una manera particular de comprender la docencia en las diferentes áreas de conocimiento, y variaciones en las percepciones de los estudiantes en cursos de la misma área de conocimiento.

Para terminar, el axioma principal de nuestra investigación es que cada docente expresa y representa su docencia de manera muy singular, a partir de sus creencias y experiencias fruto de su trayectoria personal y profesional. Las concepciones y enfoques docentes del profesorado de nuestro estudio son también particulares; podría ser que los otros académicos de las mismas universidades que no han participado en la investigación o bien académicos de otras universidades ofrecieran resultados diferentes. La investigación, por lo tanto, está limitada a un contexto y a un momento dado. Pese a esto, no podemos dejar de manifestar nuestra convicción de que en otros contextos encontraríamos enfoques docentes muy parecidos con variaciones particulares, al menos dentro el sistema universitario español.

\section{Referencias}

Åkerlind, G.S. (2003). Growing and developing as a university teacher - Variation in meaning. Studies in Higher Education, 28, 375-390.

Åkerlind, G.S. (2004). A new dimension to understanding university teaching. Teaching in Higher Education, 9, 363-376.

Åkerlind, G.S. (2005). Academic growth and development - How do university academ- ics experience it?. Higher Education, 50, 132.

Åkerlind, G.S. (2007). Constraints on academics' potential for developing as a teacher - Variation in meaning. Studies in Higher Education, 32, 21-37.

Biggs, J.B., \& Moore, P.J. (1993). The process of learning. Sydney: Prentice Hall of Australia.

Bisquerra, R. (1989). Métodos de investigación educativa. Guía práctica. Barcelona: CEAC.

Bruner, J. (1972). El Proceso de educación. México: Uteha.

Calderhead, J. (1996). Teachers' beliefs and knowledge. In R. C. Calfee and D. C. Berliner (Eds.). Handbook of educational psychology (pp. 709-725). New York: Simon and Schuster.

Carnell, E. (2007). Conceptions of effective teaching in higher education: extending the boundaries. Teaching in Higher Education, 12(1), 25-40.

Dall'Alba, G. (1991). Foreshadowing conceptions of teaching. En B. Ross (Ed.). Teaching for effective learning: research and development in higher education, 13. Sydney: Higher Education Research and Development Society of Australasia.

Dunkin, M. (1990). The induction of academic staff to a university: process and product. Higher Education, 20, 47-66.

Feixas, M. \& Castro, D. (2004). La formació del professorat al llarg de la carrera docent. Fòrum, 5, 14-19.

Feixas, M. (2002). El profesorado novel: Estudio de su problemática en la Universitat Autònoma de Barcelona. Boletín de la $R E D-U, 2,1,33-44$.

Feixas, M. (2006). Cuestionario para el análisis de la orientación docente del profesor universitario. Revista de Investigación Educativa, 24, 97-118.

Gibbs, G. \& Coffey, M. (2000). Training to teach in higher education: a research agenda. Teacher Development, 4, 31-44.

González, C. (2009). Teaching in 'blended' learning environments: How are conceptions of teaching and eTeaching associated? 
Paper presented at the ASCILITE 2009. (http://www.ascilite.org.au/conferences/auc kland09/procs/gonzalez.pdf) [Consulta 05.09.2010].

Gow L. and Kember, D. (1993). Conceptions of teaching and their relationship to student learning, British Journal of Educational Psychology, 63, 20-33.

Hativa, N. \& Goodyear, P. (2002)(Eds.). Teacher Thinking, Beliefs and Knowledge in Higher Education. London: Springer.

Johnson, R.B., \& Onwuegbuzie, A.J. (2004). Mixed methods research: A research paradigm whose time has come. Educational Researcher, 33, 7, 14-26.

Kahn, P. (2009). Contexts for teaching and the exercise of agency in early-career academics: perspectives from realist social theory. International Journal for Academic Development, 14(3), 197 - 207.

Kember, D. \& Gow, L. (1994). Orientations to teaching and their effect on the quality of student learning. Journal of Higher Education, 65, 58-73.

Kember, D. (1997). A reconceptualization of the research into university academics' conceptions of teaching. Learning and Instruction, 7, 255-275.

Kolb, D.A. (1984). Experiential learning experience as the source of learning and development. Englewood Cliffs. New Jersey: Prentice-Hall.

Kugel, P. (1993). How professors develop as teachers. Studies in Higher Education, 18, 3, 315-328.

Lindblom-Ylänne, S., Trigwell, K., Nevgi, A. and Ashwin, P. (2007). How approaches to teaching are affected by discipline and teaching context. Studies in Higher Education, 31(3), 285-291.

Marcelo, C. (1987). El pensamiento del profesor. CEAC: Barcelona.

Martin, E. \& Balla, M. (1991). Conceptions of teaching and implications for learning. En B. Ross (Ed.). Teaching for effective learning: research and development in higher education, 13. Sydney: Higher Education Research and Development Society of Australasia.
Martin, E. \& Ramsden, P. (1992). An expanding awareness: how lecturers change their understanding of teaching. En B. Ross (Ed.). Teaching for effective learning: research and development in higher education, 13. Sydney: Higher Education Research and Development Society of Australasia.

Marton, F. \& Booth, S. (1997). Learning and awareness. Mahwah: Laurence Erlbaum Associates.

Marton, F. \& Säljö, R. (1997). Approaches to learning. En Marton, F.; Hounsell, D. \& Entwistle, N. J. (Eds.): The experience of learning. Edinburgh: Edinburgh Scottish Academic Press.

Marton, F. (1990). Phenomenography: A research approach to investigating different understanings of reality. En R. Sherman \& B. Webb (Eds.). Qualitative Research in Education: Focus and Methods, $2^{\mathrm{a}}$ ed., (pp. 141-161). London: The Falmer Press.

Samuelowicz, K. \& Bain, J. (1992). Conceptions of teaching held by academic teachers, Higher Education, 24, 93-112.

Marton, F.; Hounsell, D. \& Entwistle, N. J. (1984) (Eds.). The experience of learning. Edinburgh: Edinburgh Scottish Academic Press.

Murray, K. \& Macdonald, R. (1997). The disjunction between lecturers'conceptions of teaching and their claimed educational practice. Higher Education, 33, 331-49.

Nyquist, J.D. \& Sprague, J. (1998). Thinking developmentally about Tas. En M. Marincovich, J. Prostko, \& F. Stout (Ed.). The Professional Development of Graduate Teaching Assistants. London: Anker Publishing Company.

Patton, M.Q. (1990). Qualitative evaluation and research methods. 2nd. Edition. London: Sage Publications.

Pratt, D. \& Associates (1998). Five perspectives on teaching in adult and higher education. Malabar, Florida: Kreiger.

Prosser, M. \& Trigwell, K. (1999). Understanding Learning and Teaching. Buckingham: Society for Research into Higher Education and Open University Press. 
Prosser, M. et al. (1994). A phenomenographic study of academics' conceptions of science learning and teaching, Learning and Instruction, 4, 217-231.

Ramsden, P. (1993). Learning to teach in higher education. London: Routledge.

Robertson, D.L. (1999). Profesors' perspectives on their teaching: a new construct and developmental model. Innovative Higher Education, 23, 4. 271-294.

Samuelowicz, K. \& Bain, J. (2001). Revisiting academics' beliefs about teaching and learning, Higher Education, 41, 299-395.

Schön, D.A. (1992). La formación de profesionales reflexivos. Hacia un nuevo diseño de la enseñanza y el aprendizaje en las profesiones. Barcelona: Paidós.
Trigwell, K. \& Prosser, M. (1996a). Congruence between intention and strategy in university science teachers'approaches to teaching. Higher Education, 32, 77-87.

Trigwell, K. \& Prosser, M. (1996b). Changing approaches to teaching: a relational perspective. Studies in Higher Education, 21, 275-284.

Trigwell, K. \& Prosser, M. (1999). Understanding learning and teaching. Buckingham: Society for Research into Higher Education and Open University Press.

Trigwell, K.; Prosser, M. \& Waterhouse, F. (1999). Relations between teachers' approaches to teaching and students' approaches to learning. Higher Education, 37, 57-70.

\section{ABOUT THE AUTHORS / SOBRE LOS AUTORES}

Mònica Feixas (monica.feixas@uab.cat). Licenciada en Ciencias de la Educación por la Universitat Autònoma de Barcelona (UAB), Master en Educational Administration (M.Ed.) por el Teachers College, Columbia University (1996); Doctora en Ciencias de la Educación por la UAB (2002). Profesora del Área de Didáctica y Organización Escolar del Departamento de Pedagogía Aplicada de la UAB. De entre las principales líneas de investigación figuran: culturas docentes y culturas de aprendizaje en las organizaciones de educación superior, desarrollo profesional del profesorado universitario, profesorado novel, abandono de los estudios y estrategias de retención en la universidad. Forma parte del grupo CCUC (Cambio de Cultura en la Universidad), coordinado por la Dra. Marina Tomàs y del grupo EDO (Equipo de Desarrollo Organizacional), coordinado por el Dr. Joaquín Gairín de la UAB, y del grupo Learning Cultures in Higher Education Institutions, coordinado por el Dr. Dieter Euler de la Universidad de St. Gallen (Suiza). Buscar otros artículos de esta autora en Google Académico /Find other articles by this author in Scholar Google 


\section{ARTICLE RECORD / FICHA DEL ARTÍCULO}

\begin{tabular}{|c|c|}
\hline $\begin{array}{l}\text { Reference / } \\
\text { Referencia }\end{array}$ & $\begin{array}{l}\text { Feixas, Mònica (2010). Enfoques y concepciones docentes en la universidad. RELIEVE, v. 16, n. } 2 . \\
\text { http://www.uv.es/RELIEVE/v16n2/RELIEVEv16n2_2.htm. }\end{array}$ \\
\hline Title / Título & $\begin{array}{l}\text { Enfoques y concepciones docentes en la universidad. [Teaching Approaches and Conceptions Taken by } \\
\text { University Faculty]. }\end{array}$ \\
\hline $\begin{array}{l}\text { Authors / } \\
\text { Autores }\end{array}$ & Feixas, Mònica \\
\hline $\begin{array}{l}\text { Review / } \\
\text { Revista }\end{array}$ & $\begin{array}{l}\text { RELIEVE (Revista ELectrónica de Investigación y EValuación Educativa / E-Journal of Educational Re- } \\
\text { search, Assessment and Evaluation), v. 16, n. } 2 .\end{array}$ \\
\hline ISSN & $1134-4032$ \\
\hline $\begin{array}{l}\text { Publication } \\
\text { date / } \\
\text { Fecha de } \\
\text { publicación }\end{array}$ & $\begin{array}{l}2010 \text { (Reception Date: } 2009 \text { October 2; Approval Date: } 2010 \text { September 30; Publication Date: } 2010 \\
\text { September 30). }\end{array}$ \\
\hline Abstract / & $\begin{array}{l}\text { This study aims at identifying the teaching approaches and conceptions undertaken by faculty throughout } \\
\text { their professional careers. Taking into consideration the phenomenographic research, but from a mixed- } \\
\text { method research design, our analysis shows great variability in the ways professors express and under- } \\
\text { stand their experiences and conceptions about teaching. They can be classified in: imparting knowledge, } \\
\text { motivating students, developing skills and changing students' conceptions, or a combination of these. } \\
\text { Categories are ordered from a higher to lower comprehension of teaching, and are progressive and inclu- } \\
\text { sive. Teaching approaches are not related to age, experience, discipline or appointment, although there are } \\
\text { some similarities among group. }\end{array}$ \\
\hline Resumen & $\begin{array}{l}\text { La investigación pretende conocer los enfoques y concepciones sobre docencia del profesorado universita- } \\
\text { rio a lo largo de su trayectoria profesional. Desde la fenomenografía pero con enfoque metodológico mixto, } \\
\text { nuestro análisis muestra gran variabilidad respecto cómo los docentes comprenden y expresan sus expe- } \\
\text { riencias y concepciones sobre docencia. Éstas se pueden clasificar en: impartir conocimiento, entusiasmar y } \\
\text { motivar, desarrollar habilidades y cambiar concepciones en los estudiantes; con combinaciones entre ellas. } \\
\text { Las categorías se ordenan de mayor a menor comprensión de la docencia, son progresivas e inclusivas. Los } \\
\text { enfoques docentes no tienen relación con la edad, experiencia, disciplina o categoría profesional aunque } \\
\text { existen algunas similitudes entre grupos.. }\end{array}$ \\
\hline $\begin{array}{l}\text { Keywords / } \\
\text { Descriptores }\end{array}$ & $\begin{array}{l}\text { Professional development, university teachers, academics, teaching conceptions, approaches to teaching. } \\
\text { Desarrollo profesional, profesorado universitario, enfoque docente, concepciones docentes. }\end{array}$ \\
\hline $\begin{array}{l}\text { Institution / } \\
\text { Institución }\end{array}$ & Departamento de Pedagogía Aplicada- Universitat Autònoma de Barcelona. (España). \\
\hline $\begin{array}{l}\text { Publication site } \\
\text { / Dirección }\end{array}$ & http://www.uv.es/RELIEVE \\
\hline $\begin{array}{l}\text { Language / } \\
\text { Idioma }\end{array}$ & d keywords in English) \\
\hline
\end{tabular}

\section{RELIEVE}

\section{Revista ELectrónica de Investigación y $\mathbf{E V}$ aluación Educativa E-Journal of Educational Research, Assessment and Evaluation}

[ISSN: 1134-4032]

(C) Copyright, RELIEVE. Reproduction and distribution of this articles it is authorized if the content is no modified and their origin is indicated (RELIEVE Journal, volume, number and electronic address of the document).

(C) Copyright, RELIEVE. Se autoriza la reproducción y distribución de este artículo siempre que no se modifique el contenido y se indique su origen (RELIEVE, volumen, número y dirección electrónica del documento). 